\title{
Avaliação qualitativa da implantação de práticas da produção enxuta: estudo de caso em uma fábrica de máquinas agrícolas
}

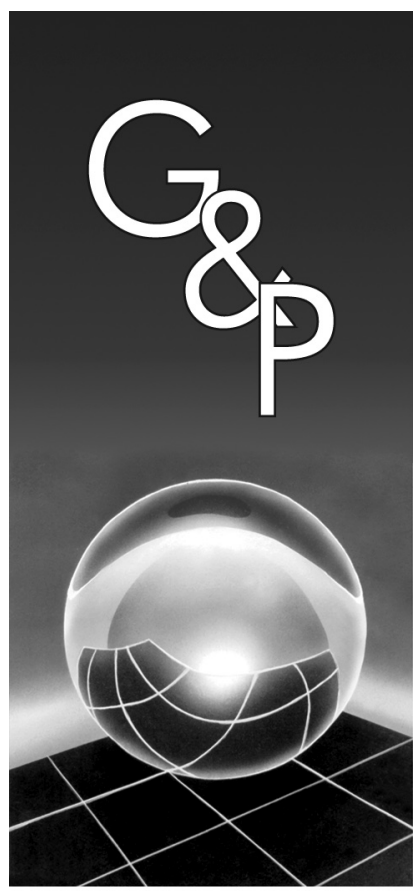

Tarcisio Abreu Saurin

Cléber Fabrício Ferreira

\begin{abstract}
Resumo
Embora a maturidade de um sistema de produção enxuta (PE) esteja associada principalmente à absorção dos princípios enxutos pela cultura organizacional, a avaliação de práticas operacionais associadas à PE fornece indícios acerca da implantação desse sistema. Este artigo apresenta uma avaliação qualitativa da implantação de práticas da PE em uma fábrica de máquinas agrícolas, a qual desde 2001 vem adotando a PE como filosofia de produção. A avaliação foi realizada na linha de montagem de colheitadeiras, usando quatro fontes de evidências: observação direta; entrevistas com 15 gerentes e supervisores; entrevistas com 30 operadores; análise de documentos relativos ao sistema de PE. Essas evidências permitiram o preenchimento de uma lista de verificação com 88 itens distribuídos ao longo de 12 típicas práticas da PE. Apesar das limitações da abordagem qualitativa utilizada (por exemplo, subjetividade na atribuição de níveis de desempenho a cada prática), foi possivel identificar pontos fortes e fracos do sistema existente na empresa. Além disso, o estudo de caso também indicou diretrizes para o aperfeiçoamento dos métodos existentes de avaliação de implantação da PE.
\end{abstract}

Palavras-chave: Produção enxuta. Medição de desempenho. Avaliação qualitativa. Indústria automotiva.

\section{Introdução}

A produção enxuta (PE) foi definida por Womack, Jones e Roos (1992) como um novo sistema de organização industrial, inspirado no Sistema Toyota de Produção (STP), que tem como meta a eliminação de qualquer perda do sistema de produção, possibilitando produtos e serviços de alta qualidade, ao menor custo possível e atendendo da melhor forma às necessidades dos clientes.

Em parte devido ao fato de que a PE teve origem empírica a partir da experiência da indústria, ainda hoje não existe consenso na literatura a respeito de quais são seus princípios e práticas fundamentais. Isso pode também ser explicado pela constante evolução desse sistema, bem como pela disseminação da PE em diversos ramos da indústria e serviços, o que por vezes têm gerado dificuldades de adaptação de conceitos. Embora diversos trabalhos venham sendo realizados com o objetivo de construir uma estrutura teórica robusta que explique e relacione de modo coerente os elementos da PE (LIKER, 2004; KOSKELA, 2000; WOMACK; JONES, 1998), a terminologia a respeito do tema também não é consensual. Enquanto autores como Picchi (2001) consideram que a PE é constituída por sistemas, filosofias e ferramentas, outros, como Pasa (2004), usam os termos princípios, leis, métodos e técnicas. Já Godinho Filho e Fernandes (2004) consideram que a PE pode ser estruturada em princípios e capacitadores. Neste artigo, são adotados os termos princípios e práticas, para fazer referência a elementos da PE com diferentes graus de abstração. Os princípios determinam os alicerces do sistema, são as regras que o sistema produtivo como um todo deve seguir. Já as práticas viabilizam a implementação dos princípios.

Dentre os princípios da PE, Womack e Jones (1998) apresentam uma proposta relativamente bem conhecida no meio acadêmico e profissional: criar valor, gerenciar a cadeia de valor, trabalhar em fluxo, puxar a produção e buscar a perfeição. Já Liker (2004) apresenta 14 princípios, tais como tomar decisões por consenso, usar controles visuais e planejar com visão de longo prazo, mesmo sob pena de prejuízos financeiros no curto prazo. Em relação às práticas, diversas são típicas da PE e têm sido objeto de estudos no Brasil e no exterior, tais como a troca rápida de ferramentas, manutenção produtiva total e produção puxada.

Os princípios e práticas da PE não devem ficar restritos ao sistema de manufatura, sendo essencial que sejam 
disseminados por todas as áreas da empresa, tais como vendas, compras, contabilidade e desenvolvimento de produto. De fato, o conceito de lean enterprise pressupõe que o pensamento enxuto seja disseminado em toda a organização, além de abranger a cadeia de suprimentos (WOMACK; JONES, 1998).

Devido à crescente disseminação do sistema de PE, surgiu a necessidade do desenvolvimento de meios para investigar seu nível de maturidade, bem como os benefícios e dificuldades enfrentadas pelas empresas. De um lado, alguns estudos têm abordado esses temas por meio de surveys. Por exemplo, White, Pearson e Wilson (1999) investigaram, nos Estados Unidos, a existência ou não de dez práticas da PE em 280 empresas de grande porte e 174 empresas de pequeno porte. Aqueles autores concluíram que três práticas (kanban, setups rápidos e operadores multifuncionais) foram decisivas para a obtenção de um bom desempenho, independente do porte da empresa. A importância das demais práticas variava conforme o porte da empresa (WHITE; PEARSON; WILSON, 1999). Um estudo similar foi conduzido por Shah e Ward (2003), os quais, a partir de questionários aplicados em 1757 empresas de diversos ramos, analisaram as correlações entre o nível de implementação de 22 práticas da PE com o porte da planta, idade da planta, existência de sindicalização dos funcionários e melhoria do desempenho operacional.

De outro lado, estudos têm sido dedicados ao desenvolvimento de propostas de avaliação do nível de implementação da PE que poderiam ser aplicadas individualmente em cada empresa, não visando à obtenção de conclusões de natureza estatística com base em surveys. Dentre essas propostas, algumas freqüentemente citadas na literatura internacional e nacional são as do Shingo Prize (SHINGO PRIZE, 1988), a de Karlsson e Ahlström (1996), o Lean Enterprise Model (LEM, 1998), as normas SAE (SOCIETY OF AUTOMOTIVE ENGINEERS, 1999a e 1999b) denominadas J4000 (identificação e medida das melhores práticas para implementação de operações enxutas) e J4001 (implementação de operações enxutas: manual do usuário), a de Sánchez e Pérez (2001) e a de Fernandes, Godinho Filho e Dias (2005).

As propostas do Shingo Prize (SHINGO PRIZE, 1988), do Lean Enterprise Model (1998) e das normas SAE têm como característica comum a origem do seu desenvolvimento. São todas originadas em iniciativas de associações profissionais, ou dessas em parceria com institutos de pesquisa, que perceberam a dificuldade das empresas na avaliação dos progressos durante a implementação da PE. Já as propostas de Karlsson e Ahlström (1996), de Sánchez e Pérez (2001) e de Fernandes, Godinho Filho e Dias (2005) são bastante similares, enfatizando a coleta e análise de indicadores de desempenho.
Entretanto, as propostas citadas não visam avaliar práticas enxutas cuja implantação ocorre diretamente e de modo visível no chão-de-fábrica (por exemplo, gerenciamento visual), mas sim princípios ligados a ações administrativas e à cultura organizacional, como, por exemplo, a criação de um ambiente favorável à aprendizagem e ao desenvolvimento de lideranças para disseminação da filosofia enxuta. Assim, considerando que, em uma situação hipotética, as práticas de nivelamento da carga de trabalho e troca rápida de ferramentas fossem aplicáveis à realidade de uma empresa que pretende ser enxuta, as propostas citadas não indicam com clareza o seu status de implementação.

Contudo, essa característica das propostas citadas justifica-se uma vez que a simples aplicação de práticas não garante que a filosofia enxuta está implementada (SPEAR; BOWEN, 1999; GHINATO, 1996). De fato, práticas como os kanbans são vistas pela Toyota apenas como contramedidas necessárias provisoriamente, enquanto as causas raízes dos problemas que exigem determinada prática não forem eliminadas (SPEAR; BOWEN, 1999). Além disso, de acordo com Womack e Jones (1998), as dificuldades enfrentadas pelas empresas que estão implementando a PE são devidas, em grande parte, à falta de compreensão acerca dos princípios fundamentais da PE.

Entretanto, a avaliação do desempenho das práticas pode, indiretamente, dar indícios da extensão da implementação dos princípios na empresa. Uma vez que a absorção dos princípios enxutos pela cultura organizacional da empresa é um processo gradual e lento, as empresas devem iniciar a transformação em direção à PE por meio da adoção das práticas enxutas (MANN, 2005). Deste modo, a avaliação da implantação das práticas faz mais sentido para empresas que estão iniciando um processo de transformação em direção à PE.

Neste contexto, considerando a necessidade de estudos que avaliem experiências de aplicação de práticas enxutas, particularmente no contexto brasileiro, este trabalho tem como objetivo principal a discussão da implantação da $\mathrm{PE}$ em uma fabricante de máquinas agrícolas que vem adotando a PE como filosofia de manufatura desde 2001. Além disso, o estudo de caso também pretende contribuir para o aperfeiçoamento dos métodos existentes de avaliação do nível de implantação da PE.

\section{Método de pesquisa}

\subsection{Contexto desta pesquisa}

Devido à dificuldade de obtenção de resultados de indicadores de desempenho da empresa estudada, a abordagem de pesquisa adotada foi principalmente qualitativa. Além disso, uma vez que o objetivo era avaliar práticas de $\mathrm{PE}$ vinculadas ao chão-de-fábrica, não foi possível adotar nenhuma das propostas de avaliação 
citadas na introdução deste artigo. O estudo de caso ocorreu como parte de outro estudo que visava avaliar os impactos da produção enxuta sobre as condições de trabalho na mesma empresa (FERREIRA, 2006). Nesse outro trabalho, um requisito importante seria a realização de um diagnóstico preliminar acerca do nível de implantação da PE que permitisse correlações qualitativas com os impactos humanos da PE. Houve certa facilidade de acesso dos pesquisadores à fábrica estudada, devido a uma parceria de oito anos entre a empresa e o grupo de pesquisa responsável pelo estudo.

\subsection{Procedimentos de coleta e análise de dados}

Embora a empresa possua várias linhas de montagem para diferentes produtos, o estudo de caso teve como foco a linha de montagem de colheitadeiras. Esta escolha levou em conta indicações da diretoria industrial, segundo a qual, nessa linha, as práticas enxutas estavam notadamente em estágio mais avançado que nos demais setores da fábrica.

Inicialmente, foi estabelecido um conjunto de típicas práticas da $\mathrm{PE}$ que seriam avaliadas, com base em trabalhos clássicos sobre o tema, tais como os de Liker (2004), Womack e Jones (1998), Shingo (1996), Womack, Jones e Roos (1992) e Monden (1984). Assim, 12 práticas foram escolhidas: produção puxada e fluxo contínuo; integração da cadeia de fornecedores; nivelamento da produção; balanceamento da produção; operações padronizadas; flexibilização da mão-de-obra; controle da qualidade zero defeitos (CQZD); manutenção produtiva total (MPT); troca rápida de ferramentas (TRF); gerenciamento visual; melhoria contínua; e mapeamento do fluxo de valor (MFV). Vale salientar que o MFV pode desempenhar uma dupla função no contexto de uma avaliação da implantação de práticas da PE. De um lado, é necessário avaliar o MFV por si só, em termos de como essa prática é implementada. De outro lado, o MFV pode cumprir papel importante como fonte de evidências para a avaliação da implantação dos princípios e práticas lean ao longo do fluxo de valor (ROTHER; SHOOK, 1998). No presente estudo, esse último papel do MFV não foi enfatizado, uma vez que os pesquisadores não tiveram acesso a detalhes dos mapas de fluxo de valor, sendo possível apenas obter informações sobre os procedimentos de aplicação dessa prática.

Com base nas práticas selecionadas, foi desenvolvida uma lista de verificação, apresentada integralmente no apêndice A, contendo 88 itens. Os itens foram estabelecidos tanto com base nos trabalhos clássicos citados, quanto com base em trabalhos de outros autores que tratavam determinadas práticas de forma mais aprofundada. Por exemplo, o trabalho de Nakajima (1989) contribuiu na prática MPT, os trabalhos de Brunet e New (2003) e Imai (1997) contribuíram na prática melhoria contínua e os trabalhos de Formoso et al. (2002), Galsworth (1997) e Greif (1991) contribuíram na prática gerenciamento visual.

É importante salientar que as práticas escolhidas foram desagregadas na lista de modo que abrangessem outras que também são comumente associadas à PE. Por exemplo, os dispositivos poka-yokes e a autonomação são avaliados como parte da prática CQZD, enquanto os programas $5 \mathrm{~S}$ são avaliados como parte da prática gerenciamento visual. A avaliação de cada item da lista, bem como as análises qualitativas realizadas, foram baseadas em quatro fontes de evidências:

a) observações diretas do trabalho na linha de montagem. A cuidadosa observação crítica do trabalho a fim de identificar oportunidades de melhoria é destacada por Liker (2004) e Spear (2004) como característica importante de uma cultura enxuta. Assim, é razoável que a observação direta também assuma papel importante como fonte de evidências em uma avaliação da implantação da PE. As observações tiveram foco nos itens apresentados na lista de verificação, uma vez que muitos eram passíveis de observação visual;

b) análise de documentos relativos ao sistema produtivo, tais como relatórios de auditorias internas, indicadores de desempenho, padrões de produção e plano de implantação do sistema;

c) entrevistas com três grupos de dez operadores da linha (24,6\% do total da linha), com duração média de 40 minutos por grupo. Embora essas entrevistas tivessem como foco avaliar os impactos humanos da PE, também geraram subsídios para a avaliação qualitativa do seu nível de implantação. Inicialmente, os operadores foram questionados acerca de quais eram os aspectos positivos ou negativos da PE do ponto de vista das condições de trabalho e o que havia mudado em relação ao antigo sistema de produção. Em seguida, o debate foi conduzido para questões específicas por meio de um roteiro que abordava pontos da PE que, com base na literatura, possivelmente teriam impacto nas condições de trabalho. Os resultados dessas entrevistas foram posteriormente discutidos com um grupo de 65 operadores para sua validação; e

d) entrevistas individuais com 15 gerentes e supervisores de diversas áreas e níveis hierárquicos da empresa. Os entrevistados foram escolhidos de acordo com seu conhecimento do assunto abordado e por representarem papel de liderança dentro de suas áreas de atuação. Além disso, suas atividades deveriam ter alguma relação com as práticas de PE abordadas nesta pesquisa. Os entrevistados foram os seguintes: quatro responsáveis pela supervisão da linha de montagem; um responsável pelo 
cálculo de recursos humanos necessários à linha de montagem; um responsável pelo estoque de materiais; um coordenador de manutenção de máquinas e equipamentos; um coordenador de compra de materiais; um coordenador de integração da cadeia de fornecedores; um coordenador de desenvolvimento do produto; um coordenador de vendas; um coordenador de suporte ao cliente; um coordenador de planejamento e controle da produção; um coordenador de qualidade; um coordenador de grupos de melhoria. As entrevistas com os gerentes foram realizadas com base nos itens da lista de verificação. Cada entrevista teve duração média de uma hora.

A partir das evidências disponíveis, o pesquisador atribuiu uma avaliação para cada item da lista, conforme os seguintes critérios: a) não se aplica (NA); b) não existe (NE), correspondendo a itens que não estão sendo aplicados, mas que, devido às características da empresa, poderiam ser adotados; c) aplicação muito fraca (MFR); d) aplicação fraca (FR); e) aplicação forte (FO); e f) aplicação muito forte (MFO). Além disso, atribuiu-se um peso a cada possibilidade de resposta, conforme segue: $\mathrm{NE}=0,0 ; \mathrm{MFR}=2,5 ; \mathrm{FR}=5,0 ; \mathrm{FO}=7,5 ; \mathrm{MFO}=10,0$. Assim, é possível calcular uma nota para cada prática usando a Equação 1.

$$
\begin{gathered}
\text { Nota }=((\mathrm{B} \times 2,5)+(\mathrm{C} \times 5,0)+(\mathrm{D} \times 7,5)+ \\
(\mathrm{E} \times 10,0)) / \mathrm{A}
\end{gathered}
$$

Em que: (A) é igual ao número de itens aplicáveis; (B) é igual ao número de itens com aplicação muito fraca; (C) é igual ao número de itens com aplicação fraca; (D) é igual ao número de itens com aplicação forte; e (E) igual ao número de itens com aplicação muito forte.

A coleta das evidências foi realizada ao longo de dez visitas à empresa durante o período de março a dezembro de 2005. As visitas tiveram duração mínima de um dia e máxima de três dias. A estimativa dos pesquisadores é que metade do tempo consumido nessas visitas foi dedicada à avaliação da implantação da $\mathrm{PE}$, sendo o tempo restante dedicado ao trabalho de avaliação dos impactos humanos da PE.

\section{Resultados e discussão}

\subsection{Caracterização da empresa}

A empresa é uma multinacional fabricante de máquinas agrícolas (colheitadeiras, tratores, plantadeiras e plataformas), com cerca de 2200 funcionários. No ano de 2001, foi iniciado um processo de remodelagem dessa unidade industrial, tendo em vista o aumento da flexibilidade de produtos e processos para o melhor atendimento das necessidades de seus clientes. Para isto, a partir da determinação e apoio técnico da matriz situada no exterior, a empresa iniciou o desenvolvimento de um sistema de produção embasado fortemente nos princípios e práticas da PE. Tal sistema está sendo implementado segundo uma lógica de gestão de projetos e possui adaptações da PE à realidade da empresa, embora seja basicamente o mesmo adotado na matriz do exterior. Existem nove áreas (ambiente de trabalho; processo operacional estruturado; tecnologia e processos de manufatura; planejamento operacional; logística de materiais; qualidade; disponibilidade operacional; gerenciamento de mudanças; treinamento; e métricas de desempenho) que compõem o novo sistema produtivo enxuto, cada uma sob responsabilidade de um gerente da própria planta. Há também uma previsão de quatro patamares de desempenho em direção à excelência em termos de manufatura enxuta (estabilização, fluxo contínuo, sincronização da produção e produção puxada, fabricação de modelos mistos conforme a demanda), sendo que cada patamar é caracterizado pelo atendimento e manutenção de determinadas metas qualitativas ou quantitativas.

As práticas da $\mathrm{PE}$ começaram a ser implantadas no setor de usinagem em 2001, mas somente em julho de 2003 a empresa começou a implementá-las no setor na montagem de colheitadeiras. Duas linhas de montagem constituem a linha de montagem de colheitadeiras: a linha de montagem principal e a de cabines. No total, trabalham nessas duas linhas 122 operadores, cada um com tempo de ciclo aproximado de 53 minutos, valor pouco inferior ao takt time da linha.

A montagem principal possui 20 estações de trabalho com cinco operadores, em média, por estação. A linha principal possui 131 metros de comprimento e $1126 \mathrm{~m}^{2}$ de área de ocupação. A linha de cabines possui 12 estações de trabalho e seis bancadas de pré-montagem, nas quais são montadas partes menores da cabine, trabalhando apenas um operador por estação ou bancada. Nas estações, as montagens ocorrem diretamente na cabine. Nas bancadas de pré-montagem, são montados itens como o ar-condicionado, coluna de direção, teto da cabine, fechaduras das portas, entre outros. Esses itens são pré-montados e disponibilizados aos montadores da linha principal. Nessa, os materiais necessários à montagem estão disponíveis em kits junto a cada estação de trabalho, sendo apenas repostos conforme vão sendo consumidos.

As colheitadeiras produzidas pela empresa são divididas em cinco famílias, diferenciadas em função do porte das máquinas. São possíveis cerca de 350 combinações para as cinco famílias, o que garante flexibilidade ao produto. A montagem da colheitadeira inicia na estação um, quando os operadores desta recebem o planejamento diário da produção que especifica as quantidades e os modelos que serão produzidos. Juntamente com o plano diário, os operadores recebem uma folha de montagem que descreve o modelo, componentes e personaliza- 
ções solicitadas pelos clientes. Esta folha segue com a máquina por todas as estações até que se conclua a montagem, reduzindo a possibilidade de troca de peças entre os modelos ou de erros na montagem. Entretanto, a folha não possui ilustrações que possam orientar os operadores. A máquina passa por inspeções de qualidade em duas estações específicas para isso, uma no meio da linha e outra fora da linha, na qual os itens defeituosos são consertados. Após a revisão final fora da linha, a máquina segue para o pátio de armazenamento ou, em alguns casos, diretamente para o embarque.

\subsection{Avaliação da implantação das práticas enxutas}

Na Figura 1, são apresentadas as notas que cada prática obteve. O controle da qualidade zero defeitos (nota 5,7) foi o item que recebeu nota mais baixa na avaliação, resultado preocupante devido a sua importância no sistema de PE. O fraco resultado se deve ao fato de que o controle de qualidade é fortemente reativo, caracterizado por ações para identificação de defeitos (ao invés de sua prevenção) e realização de ações corretivas no produto acabado. Conforme relatado pelos entrevistados, nas operações de inspeção do produto, são encontrados e registrados, em média, 34 defeitos por máquina, principalmente provenientes da própria montagem. Embora dificilmente algum desses defeitos chegue ao consumidor final, isso acaba gerando uma quantidade muito grande de retrabalho.

A empresa não adota um método científico para identificar e controlar as causas raízes dos defeitos, o que leva à repetição frequiente de problemas. Além disso, as ações corretivas adotadas não são registradas, dificultando o aprendizado com as falhas. Entretanto, aqueles defeitos que são provenientes de materiais de fornece- dores externos são registrados e cadastrados como não conformidades. Após isso, o fornecedor é contactado para que adote as devidas providências. Outros problemas importantes relativos a essa prática são os seguintes: a) treinamento informal dos operadores para identificar problemas de produtos provenientes de fornecedores; $b$ ) os operadores não têm conhecimento das metas de qualidade; e c) não são adotados dispositivos à prova de falhas (poka-yokes) na linha de montagem.

No que diz respeito à autonomação, os operadores têm autonomia para paralisar a linha quando alguma anormalidade é detectada. Entretanto, os operadores não são devidamente capacitados para tal detecção e os dispositivos visuais que sinalizam a existência de problemas são, na maioria dos casos, posicionados em locais de pouca visibilidade. Cabe salientar que o avanço das colheitadeiras através da linha acontece somente pelo acionamento dos operadores em cada estação, não seguindo um ritmo contínuo. Isso implica que atrasos do operador não o obrigam, necessariamente, a paralisar toda a linha. Nesses casos, os operadores da estação anterior ou posterior, caso já tenham concluído suas atividades, ajudam o colega atrasado.

No que se refere às operações padronizadas (nota 6,0 ), existem rotinas padrão para cada atividade de montagem, nas quais são descritas as atividades, os tempos de execução (divididos em tempo de movimentação e de trabalho), sequiências e ordens de movimentos. Embora essas rotinas estejam disponibilizadas em terminais computadorizados localizados em cada estação de trabalho, os operadores relataram que preferiam que os padrões estivessem disponíveis em documentos escritos junto às estações. Dessa maneira, segundo os operadores, as alterações nos padrões seriam feitas com maior agili-

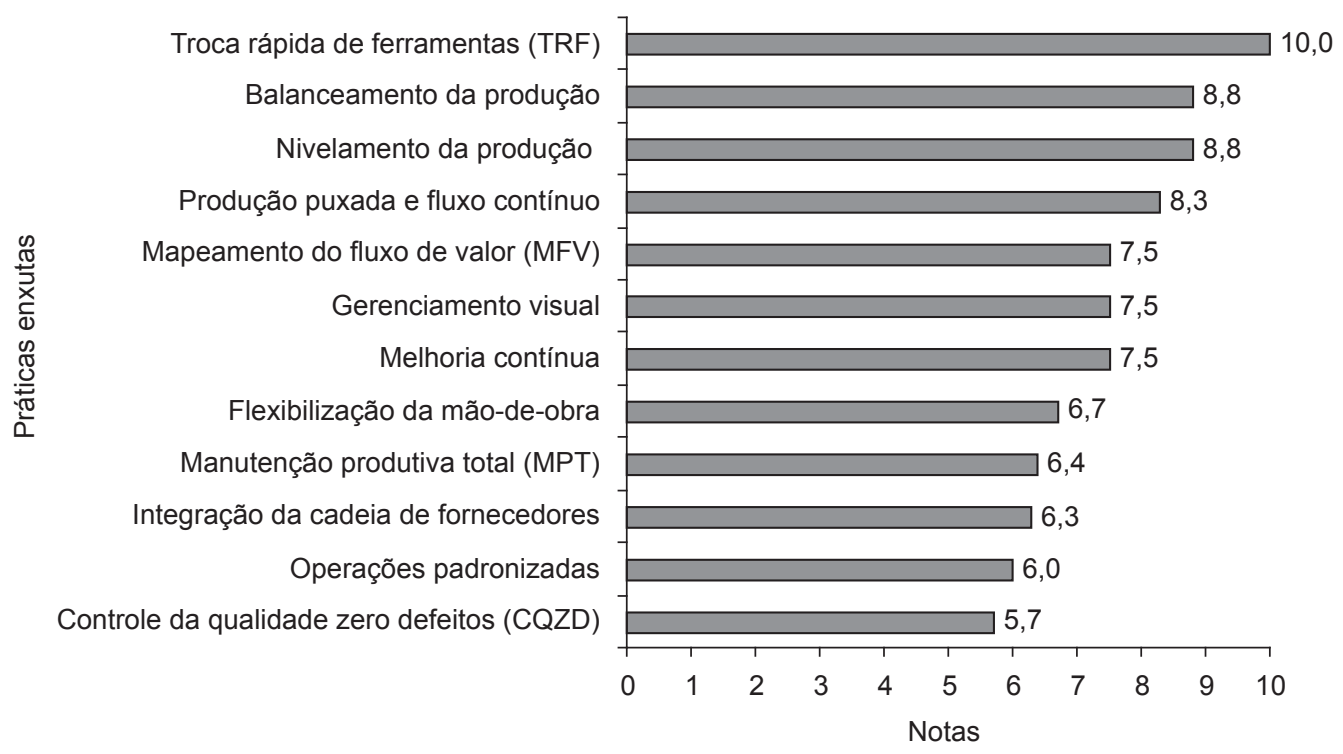

Figura 1. Notas atribuídas às práticas enxutas avaliadas. 
dade, bem como seriam evitadas situações em que as alterações são feitas no sistema, mas não são disponibilizadas nos terminais. A baixa nota dessa prática é reflexo do fato de que os padrões não são periodicamente revisados visando a melhoria contínua. Somente há revisão se ocorrem modificações de maior porte nas operações. Além disso, na maioria das vezes, os operadores não participam da elaboração dos padrões e esses, acabam, em muitos casos, por não refletir o que realmente é executado no dia-a-dia, gerando grandes diferenças entre o trabalho prescrito e o realizado. Em uma situação hipotética, segundo relatos dos operadores, caso uma colheitadeira fosse montada usando apenas o trabalho prescrito, muito provavelmente a montagem seria incompleta ou não aconteceria. Os operadores também relataram que a sequiência de movimentos padronizada para a execução das atividades, em alguns casos, podia ser facilmente alterada. Contudo, vale ressaltar que o próprio porte e a complexidade do produto montado na linha constituem fortes limitações para uma padronização mais rigorosa.

No contexto da integração da cadeia de fornecedores (nota 6,3), o planejamento de produção proporciona aos fornecedores previsões das necessidades da empresa para o futuro, ou seja, quanto se pretende comprar, qual a quantidade de material que deve ser fornecida por entrega e qual o período de entrega. Esses fornecedores mantêm contratos com a empresa nos quais assumem o compromisso de manter um estoque determinado de produtos acabados para viabilizar entregas no momento em forem solicitados, em quantidades e periodicidades cada vez menores.

A baixa nota obtida por essa prática reflete o fato de que nem todos os principais fornecedores estão operando sob o sistema just-in-time, existindo, ainda, muitos que entregam materiais em grandes lotes e com longos lead times. Em parte, isso se deve a limitações geográficas, visto que a empresa situa-se em uma região pouco industrializada, com predomínio da agricultura. Além disso, também são muito freqüentes as ocorrências de nãoconformidades de qualidade nos materiais comprados de fornecedores externos.

Na linha de montagem, é usada uma quantidade grande de equipamentos como talhas e pontes rolantes. No que diz respeito à manutenção produtiva total (nota 6,4), existe a manutenção preventiva programada daqueles equipamentos, especialmente naqueles críticos em termos de disponibilidade operacional, uso em estações gargalo, custo e segurança no trabalho. Poucos operadores, no entanto, estão aptos a realizarem atividades básicas de manutenção, como limpeza e lubrificação. Apesar de não terem sido disponibilizados dados referentes aos índices de disponibilidade operacional dos equipamentos, o supervisor do setor de manutenção e os operadores rela- taram que raramente existem quebras nos equipamentos da linha de montagem.

No aspecto referente à flexibilização da mão-de-obra (nota 6,7), a meta estabelecida pela empresa é que cada operador esteja capacitado, no mínimo, a realizar todas as atividades de sua estação, da anterior e da posterior, independente do número de atividades em cada uma. A empresa classifica os operadores em três níveis: a) treinado, para os operadores que foram treinados a executarem as atividades, mas ainda as desenvolvem sob orientação de um colega mais experiente; b) certificado, para os operadores que estão aptos a executar as atividades sem orientação; e c) mestre, para os operadores que podem treinar outros colegas ou auxiliar em diversas atividades na linha. No período da avaliação, cerca de $40 \%$ dos operadores ainda não tinham iniciado o treinamento para se tornarem multifuncionais. A empresa adotou a estratégia de fazer rodízios a cada 45 dias com os operadores já treinados, a fim de que eles não perdessem as qualificações multifuncionais por falta de prática.

A empresa tem como meta não utilizar horas-extras para absorver aumentos da demanda. Em função da grande quantidade de atividades necessárias para montar uma colheitadeira, o aumento de uma única unidade produzida por dia acarreta alterações significativas na estrutura de trabalho, sendo necessário contratar mão-de-obra. De outro lado, em períodos de baixa demanda, como foi aquele no qual ocorreu o estudo em função de secas que geraram uma crise no setor agrícola, a empresa costuma demitir uma parcela significativa da força de trabalho (cerca de 800 operadores demitidos pouco antes do início da pesquisa). De fato, durante as entrevistas os operadores revelaram ter grande receio de perder o emprego. As frequientes grandes variações de demanda na empresa estudada, tanto em função de condições climáticas extremas e sazonalidade da produção agrícola, quanto em função de fatores macro-econômicos da realidade brasileira, podem ser fortes restrições para o amadurecimento do sistema de PE, que preza pela manutenção e constante qualificação da força de trabalho em um horizonte de longo prazo. Cabe investigar se fábricas brasileiras que foram concebidas desde o seu início segundo uma lógica enxuta também tem recorrido a demissões em massa durante períodos de queda na demanda.

$\mathrm{Na}$ avaliação da prática melhoria contínua (nota 7,5), foi constatado que todos os operadores da linha estavam, na época da pesquisa, envolvidos em círculos de qualidade. Cada grupo possuía em torno de seis pessoas, sendo uma delas o líder. Os grupos eram formados de modo espontâneo pelos operadores, adotando ferramentas tradicionais de análise e resolução de problemas, como o diagrama espinha de peixe e o brainstorming. As propostas dos círculos eram avaliadas por uma comissão formada por membros da gerência e as melhores eram 
premiadas. Os prêmios correspondiam a itens com o logotipo da empresa, como roupas, objetos de uso pessoal e doméstico.

As deficiências nessa prática estavam ligadas à inconsistência entre as metas gerenciais e as ações dos grupos de melhoria, característica que não deveria existir na implantação da filosofia kaizen (BRUNET; NEW, 2003). De fato, os trabalhos desenvolvidos nos grupos de melhoria eram escolhidos segundo critérios dos trabalhadores e não tinham, necessariamente, relação com as metas da empresa, as quais por sua vez não eram disseminadas aos trabalhadores. Além disso, apesar de muitos trabalhos dos grupos de melhoria serem aprovados, foi verificado, junto à gerência e operadores, que o tempo transcorrido entre a aprovação e a implantação da melhoria, em alguns casos, passava de um ano.

No período da pesquisa, todos os membros de todas as áreas da empresa, inclusive do chão-de-fábrica, estavam participando de um curso ministrado pela própria empresa acerca dos princípios e práticas da PE. No entanto, os pesquisadores não tiveram acesso ao treinamento no sentido de avaliar se esse supre as necessidades propostas.

O gerenciamento visual (nota 7,5), que inclui a limpeza e organização do ambiente de trabalho, é o aspecto que mais impressiona em uma primeira visita à fábrica, não sendo difícil para o observador entender o fluxo do produto. A limpeza do piso da fábrica, equipamentos e prateleiras fazem parte das atribuições dos operadores, os quais são avaliados por meio de auditorias mensais quanto a aqueles aspectos.

Em termos de dispositivos visuais, é forte a presença de placas com avisos de segurança e faixas no piso para demarcar locais de armazenamento de matérias-primas e ferramentas. São também comuns os murais com gráficos de controle de qualidade, resultados de auditorias, resultados dos trabalhos dos grupos de melhoria, índices financeiros, dentre outros indicadores. No entanto, uma limitação existente, em função da estrutura física necessária para a montagem das colheitadeiras (por exemplo, pontes rolantes e cabos elétricos), é que muitos dos dispositivos visuais que ficam acima do nível do piso não são facilmente visíveis.

Existe o forte emprego de quadros sombra para a armazenagem de ferramentas que são usadas nas estações de trabalho. Outros dispositivos visuais são os kits de armazenamento de materiais, constituídos por carrinhos com desenhos e dimensões que comportam somente determinados tipos de materiais.

O mapeamento do fluxo de valor (nota 7,5) era realizado para todas as famílias de produtos (colheitadeiras) que passavam pela linha de montagem, embora fosse restrito ao fluxo de materiais dentro da planta investigada, não se estendendo aos fornecedores.
Em relação à prática de produção puxada e fluxo contínuo (nota 8,3), em virtude da grande sazonalidade da demanda, não há possibilidade da produção ser totalmente contra-pedido, como idealiza a PE. Apesar da produção de itens acabados com base em previsões ser tipicamente empurrada, a produção no chão-de-fábrica é puxada, visto que em alguns dos processos anteriores à linha de montagem (por exemplo, solda e pintura) a produção só ocorre a partir da indicação da necessidade da linha por meio de cartões kanban, localizados nos supermercados que abastecem a linha (Figura 2). Vale enfatizar que todos os setores responsáveis pelo abastecimento da linha de montagem têm uma programação de produção que especifica o que será produzido na semana. Entretanto, somente no setor de corte e dobra de chapas, a produção segue rigorosamente esse programa (é empurrada), devido à grande diversidade dos itens que são produzidos. O planejamento mestre de produção tem horizonte de dois anos, sendo desagregado em planejamento anual, trimestral, mensal e semanal. Esse planejamento assume grande importância, uma vez que alterações consistentes na demanda exigem três meses para re-planejamento da linha.

O grande porte dos produtos foi decisivo para que o arranjo físico em linha tivesse o formato de uma reta. Os deslocamentos dentro e entre estações de trabalho vizinhas são relativamente curtos, o que possibilita a comunicação direta entre os operadores. Segundo relatos dos gerentes entrevistados, o arranjo físico adotado possibilita uma grande flexibilidade, já que todos os modelos de colheitadeiras são montados na mesma linha sem a necessidade de mudanças de layout. Dentro da linha, o fluxo de produtos é contínuo, embora existam pontos específicos para eventuais acúmulos de estoque em processamento.

Tendo em vista garantir o balanceamento da produção (nota 8,8), o setor de planejamento e controle da produção (PCP) estabelece uma seqüência de produção que minimize desequilíbrios na carga de trabalho entre

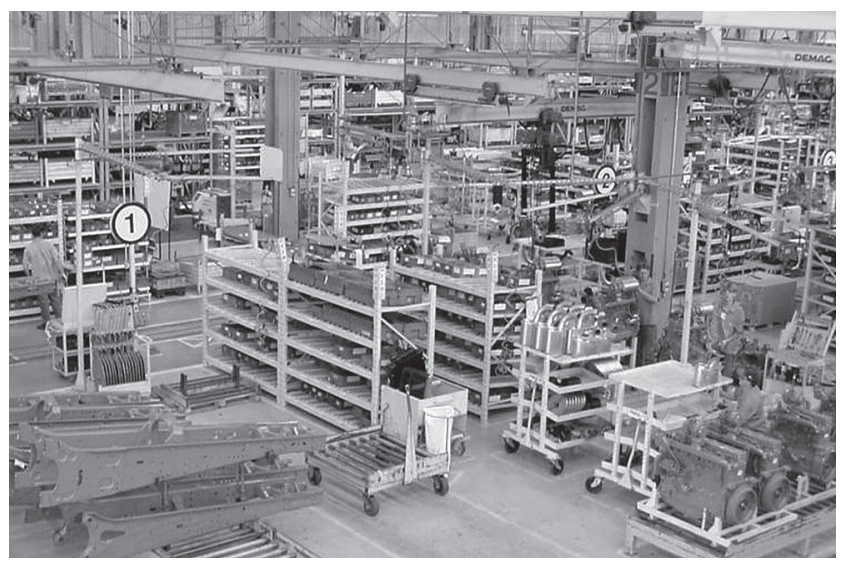

Figura 2. Supermercados de peças junto à linha de montagem. 
os operadores. Por exemplo, a montagem do modelo de maior porte só pode ser feita se for alternada com a montagem de dois modelos de menor porte. Isso limita a quantidade máxima diária de produção de cada modelo.

Contudo, existem três pontos específicos na linha, denominados pela empresa de in-process kanban (IPK), destinados à absorção de eventuais interrupções no fluxo contínuo. Na prática, o IPK é uma área entre uma estação de trabalho e outra onde há um $\mathrm{X}$ desenhado no chão (Figura 3), que funciona como um estoque temporário de produtos semi-acabados. Quando os operadores terminam as atividades na sua estação, devem encaminhar o subconjunto montado para a próxima. Caso as atividades da estação subseqüente ainda não estejam concluídas, o operador encaminha seu subconjunto para o IPK. Nessa situação, os operadores irão auxiliar os colegas que estão na estação à sua frente para restabelecer o fluxo da linha. $\mathrm{Se}$, ao retornarem a sua estação, ainda não houver material para trabalhar, os operadores devem então auxiliar os colegas da estação anterior à sua. Como regra geral, quando um IPK está preenchido, isso significa que algum problema ocorreu na linha. Em situações normais, não devem existir subconjuntos nos IPK.

Com base nas previsões de demanda, a empresa é capaz de manter o nivelamento da produção (nota 8,8), prática que garante a produção alternada dos diversos modelos de colheitadeiras. Contudo, apesar do empenho do setor de planejamento e controle da produção em garantir uma alta precisão nas suas previsões, ainda é freqüente a inserção de pedidos não previstos ou personalizações do produto. Isso acaba, em alguns casos, por perturbar o nivelamento da produção previsto.

A prática troca rápida de ferramentas obteve a nota máxima (10,0), visto que não existem setups nas trocas de modelos entre as famílias. Os materiais e equipamentos necessários à montagem dos produtos de cada família

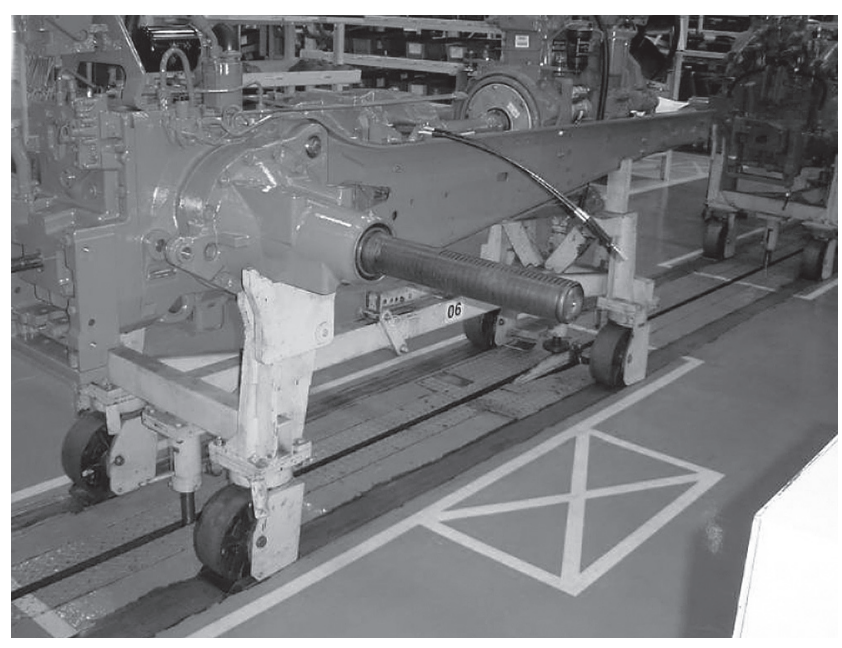

Figura 3. Área para acúmulo de estoque em processo em caso de interrupção do fluxo contínuo. estão disponíveis em contenedores junto às estações de trabalho, sendo apenas repostos na medida em que são consumidos.

A maturidade de implantação das práticas selecionadas também fornece indícios que permitem avaliar se a empresa atingiu a estabilidade básica necessária ao aprofundamento da PE. De acordo com Smalley (2006), a estabilidade básica pode ser entendida como a previsibilidade e disponibilidade constante de mão-de-obra, máquinas, materiais e métodos $(4 \mathrm{M})$. Deste modo, as deficiências identificadas na padronização de operações, evidenciadas por alguns padrões inadequados e que não são seguidos, indicam que a estabilidade em termos de métodos ainda não foi atingida. Similarmente, os problemas de qualidade com os materiais adquiridos de fornecedores externos e a ênfase reativa do controle de qualidade indicam que os materiais também são ainda fonte importante de instabilidade do sistema produtivo.

\section{Conclusões}

Este artigo apresentou uma avaliação qualitativa da implementação de 12 práticas da $\mathrm{PE}$ em uma linha de montagem de colheitadeiras. Em termos de contribuições práticas, foi apresentada uma visão geral da implantação de práticas da $\mathrm{PE}$ em uma empresa brasileira, o que, apesar da crescente disseminação dessa filosofia de produção no Brasil, não é freqüente em trabalhos acadêmicos, devido à dificuldade de acesso dos pesquisadores às empresas. Na empresa investigada, foi constatado que sete (troca rápida de ferramentas, balanceamento, nivelamento, produção puxada e fluxo contínuo, gerenciamento visual, melhoria contínua e mapeamento do fluxo de valor), dentre 12 práticas avaliadas, possuíam aplicação muito forte (nota igual ou maior que 7,5 na lista de verificação). Entretanto, nenhuma prática obteve desempenhos fracos ou muito fracos, com notas abaixo de 5,0. A prática com desempenho mais fraco foi o controle da qualidade, visto que a empresa focava mais na inspeção do produto final do que em inspeções integradas ao processamento. Contudo, é importante enfatizar que, em função da subjetividade da atribuição de notas, bem como do fato de que os itens da lista não são exaustivos, a análise qualitativa deve ser mais valorizada do que as notas no contexto da abordagem usada neste trabalho.

Sob o ponto de vista da PE como um conjunto abrangente de práticas e princípios, também é necessário reconhecer que este trabalho não avaliou diretamente a implantação dos princípios da PE, o que de fato indicaria com mais precisão a maturidade do sistema. Entretanto, análises qualitativas indiretas acerca dos princípios podem ser realizadas com base no desempenho das práticas. Por exemplo, a repetição freqüente dos mesmos problemas de qualidade indica que o princípio da busca pela perfeição 
deixa a desejar nesse aspecto. Já o princípio de puxar a produção está bem disseminado no que se refere à comunicação entre os processos internos da fábrica. $\mathrm{O}$ princípio de gerenciamento da cadeia de valor está sendo trabalhado por meio da parceria com fornecedores para redução de frequiências de entrega e tamanhos de lotes. Já em relação ao princípio criar valor, a avaliação de sua implementação necessitaria de entrevistas mais aprofundadas junto aos setores de desenvolvimento de produtos, assistência técnica e vendas da empresa.

Em termos de contribuições teóricas, a abordagem qualitativa pode contribuir para o desenvolvimento de métodos de avaliação de práticas da PE que combinem evidências quantitativas e qualitativas. Os trabalhos anteriores acerca de avaliação do nível de implantação da $\mathrm{PE}$ não enfatizavam a avaliação direta de práticas da $\mathrm{PE}$ ligadas ao chão-de-fábrica, como feito neste estudo, bem como muitos eram baseados em surveys, sem contato direto dos pesquisadores com a empresa. Além disso, as propostas disponíveis na literatura para avaliação da PE com base em indicadores de desempenho não têm sido validadas empiricamente, talvez em parte pelo desejo das empresas em manter sigilo desses dados.

Considerando o método adotado neste estudo, a lista de verificação de práticas da $\mathrm{PE}$ revelou ser um bom instrumento para orientar entrevistas e observações de campo, embora outras práticas e itens possam ser adicionados em estudos futuros (por exemplo, logística lean). Em que pese a subjetividade das categorias de avaliação da lista, o preenchimento com base em múltiplas evidências visa reduzir essa limitação. Como oportunidade para tornar mais consistente a atribuição de notas na lista, cada item de avaliação poderia ser adicionalmente desagregado em categorias com descrições qualitativas acerca das características, por exemplo, de um desempenho forte ou fraco. Além disso, após a atribuição de notas pelo auditor, elas poderiam ser validadas junto aos entrevistados. Nesse sentido, é essencial que uma avaliação da implantação de práticas da PE inclua entrevistas junto aos operadores, especialmente para identificar as diferenças entre o trabalho real e o trabalho prescrito, geralmente mais enfatizado pelos gerentes. Neste estudo, essa importância ficou clara na análise da prática de operações padronizadas, quando os operadores revelaram que os padrões não costumam ser seguidos, em função de falhas na sua elaboração.

Outras limitações da abordagem utilizada neste trabalho foram as seguintes: a) não atribuição de um grau de importância para cada prática, no contexto da realidade da empresa; e b) tempo despendido com entrevistas junto a gerentes e trabalhadores, estimado em cerca de treze horas, sem considerar o tempo gasto na análise de dados. Em relação a esse último aspecto, o estudo de caso também revelou a adequação da proposta de avaliar a PE separadamente por setores da empresa, o que permitiu aprofundar a análise, especialmente em uma fábrica de grande porte como a estudada.

\title{
Qualitative assessment of the implementation of lean production practices: a case study in a heavy machinery manufacturer
}

\begin{abstract}
Even though the maturity of lean production $(L P)$ systems is mostly associated with the integration of lean principles into the organizational culture, the assessment of shop-floor practices associated with LP provides an overview of how lean a company is. In this context, this study presents a qualitative assessment of the implementation of LP practices in a heavy machinery manufacturer that has been adopting LP as its production philosophy since 2001. The assessment was undertaken in the harvesters assembly line based on four sources of evidence: direct observation; interviews with fifteen managers and supervisors; interviews with thirty operatives; and analysis of documents related to the LP system. Those evidences were a basis for fulfilling a checklist with eighty-eight items distributed among twelve typical lean practices. Regardless of the shortcomings of the qualitative approach adopted, such as the subjectivity involved in the assignment of performance levels for each practice, it was possible to identify strengths and weaknesses of the existing lean system. Moreover, this study also pointed out guidelines to improve existing LP assessment methods.
\end{abstract}

Keywords: Lean production. Performance measurement. Qualitative assessment. Automotive industry. 
BRUNET, A.; NEW, S. Kaizen in Japan: an empirical study. International Journal of Operations and Production Management, v.23, n.12, p. 1426-1446, 2003.

FERNANDES, F. C. F.; GODINHO FILHO, M.; DIAS, F. T. Proposta de um método baseado em indicadores de desempenho para avaliação de princípios relativos a manufatura enxuta. In: Encontro Nacional de Engenharia de Produção, 25. Anais... UFRGS, Porto Alegre, RS, 2005.

FERREIRA, C. F. Diretrizes para avaliação dos impactos da produção enxuta sobre as condições de trabalho. Porto Alegre: UFRGS, 2006. Dissertação de Mestrado em Engenharia de Produção, Escola de Engenharia, Universidade Federal do Rio Grande do Sul, 2006.

FORMOSO, C.T.; SANTOS, A.; POWELL, J. An exploratory study on the applicability of process transparency in construction sites, Journal of Construction Research, v.3 n.1, p. 35-54, 2002.

GALSWORTH, G. Visual systems: harnessing the power of the visual workplace, American Management Association, New York, 1997, $320 \mathrm{p}$.

GHINATO, P. Sistema Toyota de Produção: mais que simplesmente Just-in-Time. Editora da Universidade de Caxias do Sul: Caxias do Sul, 1996.

GODINHO FILHO, M.; FERNANDES, F. C. F. Manufatura enxuta: uma revisão que classifica e analisa os trabalhos apontando perspectivas de pesquisas futuras. Gestão \& Produção. V.11, p.1-19, 2004.

GREIF, M. The visual factory: building participation through shared information. Boston: Productivity Press, 1991.

IMAI, M. Gemba kaizen: a common sense, low cost approach to management. New York: McGraw-Hill, 1997.

KARLSSON, C.; AHLSTRÖM, P. Assessing changes towards lean production. International Journal of Operations and Production Management. v. 16, 1996.

KOSKELA, L. An Exploration Towards a Production Theory and Its Application to Construction. Espoo. Technical Research Centre of Finland, VTT Pub. 408, 296 p., 2000.

LEAN ENTERPRISE MODEL - LEM (1998). Lean Aerospace Initiative (LAI). Disponível em: http://web.mit.edu/lean/. Acessado em 06/07/2005.

LIKER, J. The Toyota Way: 14 management principles from the world's greatest manufacturer. McGraw-Hill, 2004.

MANN, D. Creating a lean culture: tools to sustain lean conversions. New York: Productivity Press, 2005.

MONDEN, Y. Toyota production system: practical approach to production management. Norcross: Industrial Engineering and Management Press, 3 ed., 1998.
NAKAJIMA, S. Introdução ao TPM: Total Productive Maintenance. São Paulo: Internacional Sistemas Educativos, 1989.

PASA, G. S. Uma Abordagem para Avaliar a Consistência Teórica de Sistemas Produtivos. Porto Alegre: UFRGS, 2004. Tese de Doutorado em Engenharia de Produção, Escola de Engenharia, Universidade Federal do Rio Grande do Sul, 2004.

PICCHI, F. A. Lean Thinking (mentalidade enxuta): avaliação sistemática do potencial de aplicação no setor de construção. In: II SIBRAGEC. Anais... Antac. Fortaleza, 2001.

ROTHER, M; SHOOK, J. Learning to see: value stream mapping to create value and eliminate muda. Massachusetts : Brookline, $1998.96 \mathrm{p}$.

SÁNCHEZ,M.A.; PÉREZ, M.P. Lean indicators and manufacturing strategies. International Journal of Operations \& Production Management. v.21, n.11, p.1433-1451, 2001.

SHAH, R.; WARD, P. T. Lean manufacturing: context, practice bundles, and performance. Journal of Operations Management, V.21, p.129-149, 2003.

SHINGO PRIZE. Recognizing Business Excellence in the United States, Canada and Mexico: application guidelines, 1988. Disponível em: http://www.shingoprize.org/ Acessado em: 22/08/2005.

SHINGO, S. O Sistema Toyota de Produção do Ponto de Vista da Engenharia de Produção. Bookman: Porto Alegre, 1996.

SMALLEY, A. Basic stability is basic to lean manufacturing success. Disponível em: http://www.lean.org.br/bases. php?\&interno=artigo_20. Acessado em 07/06/2006.

SOCIETY OF AUTOMOTIVE ENGINEERS. Identification and measurement of best practices for implementing lean operations (SAE standard J4000). 1999a.

SOCIETY OF AUTOMOTIVE ENGINEERS. Implementation of lean operations: user manual (SAE standard J4001). 1999b.

SPEAR, S. Learning to lead at Toyota. Harvard Business Review, p.1-10, May, 2004.

SPEAR, S.; BOWEN, H. Decoding the DNA of the Toyota Production System. Harvard Business Review, p. 97-106, sep 1999.

WHITE, R. E.; PEARSON, J. N.; WILSON, J. R. JIT manufacturing: a survey of implementations in small and large U.S. manufacturers. Management Science. Linthicum: V.45, Iss.1, p.1-15, 1999.

WOMACK, J.; JONES, D.; ROOS, D. A Máquina que Mudou o Mundo. Editora Campus: Rio de Janeiro, 1992.

WOMACK, J; JONES, D. Lean thinking: banish waste and create wealth in your corporation. Simon and Schuster: New York, 1998. 


\section{Apêndice}

Tabela 1. Lista de verificação para avaliação da implantação de práticas da produção enxuta (a lista está preenchida com base nos resultados do estudo de caso).

\begin{tabular}{|c|c|c|c|c|c|c|c|}
\hline & & NA & NE & MFR & FR & FO & MFO \\
\hline 1 & Produção puxada e fluxo contínuo & & & & & & \\
\hline 1.1 & Somente uma operação recebe a ordem de produção emitida pelo setor de PCP & & & & & & $\mathrm{X}$ \\
\hline 1.2 & Todas as ordens de produção correspondem a pedidos firmes de clientes & & & $\mathrm{X}$ & & & \\
\hline 1.3 & $\begin{array}{l}\text { É adotada uma fórmula para dimensionar supermercados (ou estoques tipo FIFO) } \\
\text { de produtos acabados e semi-processados, a qual considere no mínimo os parâme- } \\
\text { tros demanda média diária, variação da demanda, coeficiente de segurança e lead } \\
\text { time de reposição }\end{array}$ & & & & & $\mathrm{X}$ & \\
\hline 1.4 & $\begin{array}{l}\text { A entrega de produtos acabados aos clientes finais é realizada dentro do prazo } \\
\text { prometido }\end{array}$ & & & & & & $\mathrm{X}$ \\
\hline 1.5 & $\begin{array}{l}\text { Existe baixa variabilidade nos lead times de produção, garantindo maior confiabi- } \\
\text { lidade acerca da capacidade de produção e prazos de entrega (lead time ou tempo } \\
\text { de atravessamento é o tempo decorrido desde o pedido efetuado pelo cliente até a } \\
\text { entrega do produto) }\end{array}$ & & & & & & $\mathrm{X}$ \\
\hline 1.6 & $\begin{array}{l}\text { Há dispositivos para puxar a produção entre células, linhas ou ambientes job-shop, } \\
\text { tais como cartões kanban ou FIFO }\end{array}$ & & & & & & $\mathrm{X}$ \\
\hline 1.7 & Há dispositivos visuais que permitem identificar as prioridades de produção & & & & $\mathrm{X}$ & & \\
\hline 1.8 & $\begin{array}{l}\text { Havendo uso de cartões kanban, eles contêm identificação do item, quantidade e } \\
\text { endereço de armazenamento }\end{array}$ & & & & & & $\mathrm{X}$ \\
\hline 1.9 & $\begin{array}{l}\text { Havendo uso de cartões kanban, o processo subsequiente retira do processo prece- } \\
\text { dente os itens de sua necessidade apenas nas quantidades e no tempo necessário }\end{array}$ & & & & & & $\mathrm{X}$ \\
\hline 1.10 & $\begin{array}{l}\text { Os processos só produzem o que é indicado no kanban de produção ou até o preen- } \\
\text { chimento do espaço FIFO subseqüente }\end{array}$ & & & & & & $\mathrm{X}$ \\
\hline 1.11 & Os itens defeituosos não seguem para o processo seguinte & & & & $\mathrm{X}$ & & \\
\hline 1.12 & $\begin{array}{l}\text { O número de kanbans é periodicamente reduzido. Estime a periodicidade de redu- } \\
\text { ção do número de kanbans: __ Quando foi a última redução? }\end{array}$ & & & $\mathrm{X}$ & & & \\
\hline 1.13 & Há fluxo contínuo e unitário entre processos consecutivos & & & & & $\mathrm{X}$ & \\
\hline 1.14 & $\begin{array}{l}\text { O takt time é conhecido (takt time é o tempo total disponível por dia dividido pela } \\
\text { demanda diária) }\end{array}$ & & & & & & $\mathrm{X}$ \\
\hline 1.15 & Os tempos de ciclo são conhecidos e padronizados & & & & & & $\mathrm{X}$ \\
\hline 1.16 & Os lead times de produção de cada produto são conhecidos & & & & & & $X$ \\
\hline 1.17 & $\begin{array}{l}\text { Os tempos de ciclo equivalentes (média ponderada dos tempos de ciclo de todos os } \\
\text { produtos) em cada posto de trabalho são menores que o takt time }\end{array}$ & & & & & & $\mathrm{X}$ \\
\hline 1.18 & $\begin{array}{l}\text { Há dedicação dos recursos (equipamentos ou pessoas) para a fabricação de famí- } \\
\text { lias de produtos que possuem processos semelhantes }\end{array}$ & & & & & & $\mathrm{X}$ \\
\hline 1.19 & $\begin{array}{l}\text { O arranjo físico dos postos de trabalho favorece a produção e transporte de peque- } \\
\text { nos lotes }\end{array}$ & & & & & $\mathrm{X}$ & \\
\hline 2 & Integração da cadeia de fornecedores & & & & & & \\
\hline 2.1 & $\begin{array}{l}\text { Os fornecedores fazem entregas em pequenos lotes e com grande freqüência. Esti- } \\
\text { me a periodicidade de entrega de alguns fornecedores-chave: }\end{array}$ & & & & & $\mathrm{X}$ & \\
\hline 2.2 & As entregas dos fornecedores são puxadas ao invés de empurradas & & & & & $\mathrm{X}$ & \\
\hline 2.3 & $\begin{array}{l}\text { Os dispositivos para puxar as entregas dos fornecedores externos contêm infor- } \\
\text { mação sobre o que é pedido, em que momento deve chegar (dia e hora), em que } \\
\text { quantidade e onde armazenar }\end{array}$ & & & & & $\mathrm{X}$ & \\
\hline 2.4 & $\begin{array}{l}\text { Os fornecedores-chave adotam técnicas que asseguram a qualidade de seus produ- } \\
\text { tos, dispensando inspeções de qualidade no momento do recebimento }\end{array}$ & & & $\mathrm{X}$ & & & \\
\hline 3 & Operações padronizadas & & & & & & \\
\hline 3.1 & $\begin{array}{l}\text { Existem rotinas-padrão para todas as operações (rotinas-padrão são documentos } \\
\text { que descrevem o conteúdo, tempos, movimentos e resultados de cada operação) }\end{array}$ & & & & & & $\mathrm{X}$ \\
\hline 3.2 & $\begin{array}{l}\text { Existem folhas de operação-padrão (folhas de operação-padrão são documentos que } \\
\text { apresentam a quantidade máxima permitida de material em processamento, pontos } \\
\text { de inspeção de qualidade, takt time, tempo de ciclo e layout da célula ou linha) }\end{array}$ & & & & & $\mathrm{X}$ & \\
\hline
\end{tabular}


Tabela 1. Continuação...

\begin{tabular}{|c|c|c|c|c|c|c|c|}
\hline & & NA & NE & MFR & FR & FO & MFO \\
\hline 3.3 & $\begin{array}{l}\text { As folhas de operação-padrão e rotinas-padrão são periodicamente revisadas e } \\
\text { comunicadas aos usuários? Estimar a periodicidade: }\end{array}$ & & & $\mathrm{X}$ & & & \\
\hline 3.4 & $\begin{array}{l}\text { Os funcionários participam ativamente da elaboração dos padrões, de forma que } \\
\text { sejam incorporados a eles suas experiências }\end{array}$ & & & $\mathrm{X}$ & & & \\
\hline 3.5 & $\begin{array}{l}\text { Os padrões estão em locais de fácil acesso a todos, permitindo sua consulta de } \\
\text { forma rápida e clara }\end{array}$ & & & & & $\mathrm{X}$ & \\
\hline 4 & Nivelamento da produção & & & & & & \\
\hline 4.1 & $\begin{array}{l}\text { Considerando um horizonte de uma semana, existe uma programação nivelada de } \\
\text { produção pelo seqüenciamento de ordens de produção em um padrão repetitivo de } \\
\text { mix e volume }\end{array}$ & & & & & & $\mathrm{X}$ \\
\hline 4.2 & Considerando um horizonte de 7 a 30 dias, existe uma programação nivelada de & & & & & & $\mathrm{X}$ \\
\hline
\end{tabular}
produção (seqüenciamento de ordens de produção em um padrão repetitivo de mix e volume)

4.3 Considerando um horizonte de 30 a 90 dias, existe uma programação nivelada de produção (seqüenciamento de ordens de produção em um padrão repetitivo de mix e volume)

4.4 Inexistem variações grandes e rápidas (por exemplo, por meio da introdução de pedidos emergenciais) no mix de modelos e volumes de produção

5 Balanceamento da produção

5.1 Os tempos de ciclo dos diversos postos são balanceados

5.2 Os tempos de ciclo das linhas ou células são balanceados $\mathrm{X}$

$6 \quad$ Flexibilização da mão-de-obra

6.1 Existe proximidade física entre a execução das operações, permitindo que os operadores estejam próximos o bastante para transferir materiais facilmente e possam realizar operações multifuncionais

6.2 Os operadores têm oportunidade de exercitar suas habilidades multifuncionais. Estime a periodicidade em que ocorre rotação entre postos de trabalho:

6.3 O índice de multifuncionalidade (IM) está entre: 0 e 25\% (fraco); 26,1 e 50\% (moderado); 50,1 e 75\% (forte); 75,1 e 100\% (muito forte)

$7 \quad$ Controle da qualidade zero defeitos (CQZD)

7.1 Os processos estão sob controle, apresentando baixa variabilidade e esta é reduzida continuamente

7.2 É reduzido o tempo decorrido entre a detecção de uma anormalidade e a aplicação da ação corretiva

7.3 Há identificação e combate às causas raízes de defeitos (causas raízes são os problemas que deram início ao encadeamento de acontecimentos que gerou o defeito)

7.4 Há baixo índice de retrabalho

7.5 Existem especificações documentadas a respeito das características de qualidade dos produtos

7.6 Existem auditorias de qualidade

7.7 É usada preferencialmente inspeção na fonte (identificar e manter sob controle os erros geradores dos defeitos) ao invés de inspeção informativa (ocorre o defeito e todas as informações a seu respeito são transmitidas ao responsável para que medidas sejam adotadas)

7.8 Existem indicadores de processo e resultados relativos à qualidade. Citar os principais:

7.9 São freqüientes as combinações de poka-yoke + inspeção na fonte + ação imediata

7.10 Há inspeção de qualidade em $100 \%$ dos itens

7.11 As máquinas são dotadas de dispositivos que detectam anormalidades, tais como peças defeituosas ou quebras

7.12 As máquinas param automaticamente quando alguma anormalidade é detectada

7.13 Os funcionários têm autonomia de paralisar a linha, parcial ou totalmente, bem como solicitar ajuda quando alguma anormalidade é detectada

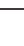


Tabela 1. Continuação...

\begin{tabular}{|c|c|c|c|c|c|c|c|}
\hline & & NA & NE & MFR & FR & FO & MFO \\
\hline 7.14 & $\begin{array}{l}\text { Há painéis sinalizadores para indicar os postos paralisados ou que necessitam de } \\
\text { auxílio }\end{array}$ & & & & & $\mathrm{X}$ & \\
\hline 8 & Manutenção produtiva total (MTP) & & & & & & \\
\hline 8.1 & Há preferência pela manutenção preventiva, ao invés de manutenção corretiva & & & & & $\mathrm{X}$ & \\
\hline 8.2 & $\begin{array}{l}\text { Existe manutenção autônoma, ou seja, os operadores são capacitados a executar a ma- } \\
\text { nutenção preventiva básica de suas máquinas (inspeção diária, lubrificações e limpezas) }\end{array}$ & & & & $\mathrm{X}$ & & \\
\hline 8.3 & $\begin{array}{l}\text { Os funcionários são treinados para detectarem anormalidades nas máquinas e } \\
\text { equipamentos que usam em seu trabalho }\end{array}$ & & & & $\mathrm{X}$ & & \\
\hline 8.4 & $\begin{array}{l}\text { O indicador OEE (operational equipment effectiveness) é coletado diariamente em } \\
\text { máquinas priorizadas segundo critérios objetivos (por exemplo, baixa capacidade } \\
\text { de produção, ausência de redundância ou riscos de acidentes) }\end{array}$ & & & & $\mathrm{X}$ & & \\
\hline 8.5 & $\begin{array}{l}\text { As causas de ineficiências das máquinas priorizadas para coleta do OEE são regis- } \\
\text { tradas, priorizadas e ações corretivas são adotadas }\end{array}$ & & & & & $X$ & \\
\hline 8.6 & Existem listas de verificações para orientar as atividades de manutenção & & & & $\mathrm{X}$ & & \\
\hline 8.7 & $\begin{array}{l}\text { Existe planejamento acerca de qual o melhor método de manutenção de cada má- } \\
\text { quina, com base em seus modos de falha previstos }\end{array}$ & & & $X$ & & & \\
\hline 9 & Troca rápida de ferramentas (TRF) & & & & & & \\
\hline
\end{tabular}
(setup externo envolve atividades que podem ser executadas enquanto a máquina está funcionando e setup interno envolve atividades que só podem ser executadas enquanto a máquina está parada)

9.2 Existem padrões escritos que identificam e separam claramente atividades de setup $\quad \mathrm{X}$ interno e externo

9.3 Quando os equipamentos estão parados, os operadores nunca os deixam para exe- $\quad$ X cutar qualquer parte da troca externa de ferramenta

9.4 Na preparação externa, as ferramentas, dispositivos de fixação e os materiais são $\quad$ X posicionados próximos à máquina

9.5 Na preparação interna, somente a remoção e a colocação de ferramentas são feitas $\quad \mathrm{X}$

9.6 São estudadas, freqüentemente, medidas para eliminação de ajustes desnecessários $\quad \mathrm{X}$ (por exemplo, evitar o uso de parafusos e porcas de tamanhos diferentes, redução do número de roscas, redução do número de orifícios)

9.7 Existe espaço suficiente ao redor das máquinas para facilitar a movimentação dos $\quad \mathrm{X}$ operadores durante os setups

9.8 Inexiste a necessidade de levantar peças pesadas manualmente durante as trocas $\quad \mathrm{X}$

9.9 Existem procedimentos para priorização de máquinas nas quais serão concentrados $\quad \mathrm{X}$ os esforços de TRF

10 Gerenciamento visual

10.1 O fluxo dos processos é visível e compreensível do início ao fim

10.2 O uso de dispositivos visuais (por exemplo, placas, alarmes, faixas no piso e dispositivos à prova de erros) é disseminado para o compartilhamento de informações

10.3 Inexistem obstáculos visuais (por exemplo, paredes, prateleiras, pouca iluminação, layouts confusos) que dificultem o compartilhamento de informações entre processos

10.4 Os indicadores de processo (principalmente) e resultado são amplamente divulgados aos operadores

10.5 As informações compartilhadas por meio de gerenciamento visual são necessárias aos operadores para realização de suas tarefas

10.6 As informações compartilhadas por meio de gerenciamento visual são facilmente acessíveis aos operadores

10.7 São freqüentes as ações de gerenciamento visual que fornecem feedback em tempo real aos operadores

10.8 Existe aplicação de programas 5S ou similar

11.1 Existem atividades em pequenos grupos (APG). Quais os principais assuntos tratados nas APG? 
Tabela 1. Continuação...

11.2 Periodicamente, ocorrem kaizens workshops (eventos caracterizados por trabalho NA

\begin{tabular}{|c|c|c|c|c|}
\hline NE & MFR & FR & FO & MFO \\
\hline
\end{tabular}
intensivo, brainstorming e envolvimento de equipes, geralmente de 4 a 5 dias de duração, nos quais os membros tentam alcançar o máximo de melhoria de uma atividade ou processo)

11.3 As melhorias realizadas são sempre padronizadas

11.4 Os grupos de melhoria contínua utilizam ferramentas estruturadas para aná-

$\mathrm{X}$ lise e solução de problemas, tais como $5 \mathrm{~W} 2 \mathrm{H}$, diagrama espinha de peixe ou brainstorming

11.5 As metas da empresa são desdobradas de forma clara e objetiva, a fim de que as ações de melhoria contínua contribuam para que elas sejam atingidas

11.6 As metas da empresa estão claramente definidas e são comunicadas a todos na organização

11.7 Todos os membros da organização são treinados para terem conhecimento da filosofia, princípios e práticas básicas da produção enxuta

11.8 Os operadores recebem algum tipo de recompensa, financeira ou não, pela participação em atividades de melhoria contínua

11.9 A alta gerência está envolvida diretamente com os programas de melhoria

12 Mapeamento do fluxo de valor (MFV)

12.1 Existem mapas do estado atual e do estado futuro para todas as famílias de produtos

12.2 Existem planos de ação para implantar os mapas do estado futuro, com designação de responsabilidades e prazos

12.3 Os mapas do estado atual e do estado futuro são elaborados e analisados por uma equipe com representantes de todas as áreas da empresa envolvidas no fluxo de valor

12.4 O mapeamento do fluxo de valor não se restringe ao nível porta-a-porta, também incluindo a cadeia de suprimentos

\section{Sobre os autores}

\section{Tarcisio Abreu Saurin}

\section{Cléber Fabrício Ferreira}

Programa de Pós-Graduação em Engenharia de Produção - PPGEP,

Laboratório de Otimização de Produtos e Processos - LOPP,

Universidade Federal do Rio Grande do Sul - UFRGS,

Av. Osvaldo Aranha, 99, $5^{\circ}$ andar, Centro, CEP 90035-190, Porto Alegre, RS, Brasil,

e-mails: saurin@ufrgs.br; tasaurin@terra.com.br; cleber@producao.ufrgs.br 